\begin{tabular}{c} 
International Journal of Engineering \& Technology, $7(2.2)(2018) 112-116$ \\
International Journal of Engineering \& Technology \\
SPC \\
Website: www.sciencepubco.com/index.php/IJET \\
Research Paper \\
\hline
\end{tabular}

\title{
Line Follower Robot Optimization based Fuzzy Logic Controller Using Membership Function Tuning
}

\author{
Supriadi Supriadi ${ }^{1}$, Ansar Rizal ${ }^{2}$, Didi Susilo Budi Utomo ${ }^{3}$, Agusma Wajiansyah** \\ 1,2,3,4 Department of Information Technology, State Polytechnic of Samarinda, East Kalimantan, Indonesia \\ *Corresponding author E-mail: agusma.wajiansyah@gmail.com
}

\begin{abstract}
The study was aimed to measure the performance of Fuzzy Logic Controller (FLC) on Line Follower Robot (LFR). FLC output is a deviation value of Pulse Width Modulation (PWM) to determine the rotational speed of the left and the right wheel. As input variables are current and previous line sensors. Tuning was applied to input and output variables in each membership function (MF) to conduct the best performance. This study used triangular membership function that consists of three MF. Mamdani Fuzzy Inference System (FIS) is used using nine rules. The result obtains that after MF tuning, the performance of the LFR settling time is $0.63 \mathrm{~s}$ faster compare to that without tuning.
\end{abstract}

Keywords: Fuzzy Logic Controller, Line Follower Robot, Mamdani.

\section{Introduction}

Line follower robot (LFR) is an electronic system that can follow lines, where the line is visible or invisible. Generally, a line is a predetermined path that can be detected by the sensor[1][2]. LFR has a wide implementation in many different areas such as hospitals[1][3], restaurants[4] and as household devices[4]. LFR requires a certain way to move along the line, some of it is bang-bang control, PID method[5], or intelligent approach methods[6]. One of common LFR controlling based on intelligent approach methods is FLC [6][7][8][9][10][11][12][13]. This study exploits the performance of embedded FLC on LFR to reach its settling time. Settling time is the time required for the response to reach and remain within a specified tolerance limit around the steady-state value.

FLC consists of the following four elements[14]:

1. A rule-base, which contains the quantification of fuzzy logic from an expert linguistic description of how to achieve good control.

2. An inference mechanism, which emulates expert decisions in interpreting and applying knowledge of how best to control the plant.

3. A fuzzification, which converts the controller input into information that the inference mechanism can be easily used to enable and apply rules.

4. A defuzzification, which turns the inference mechanism into actual input for the plant.

The commonly used technique for defuzzification is the centroid method[14]. Using the centroid algorithm shown in Equation (2), where $n$ is the number of sample elements, $x_{i}$ is the elements and $\mu\left(x_{i}\right)$ is the MF value paired with $x_{i}$. In this experiment, input and output variables use both triangular membership functions, as in Equation (1). Triangular curves depend on three parameters $a, b$, and c [15]. Fig. 1 shows triangular membership functions.

$$
f(x ; a, b, c)= \begin{cases}0 & \text { for } c<x<a \\ \frac{x-a}{b-a} & \text { for } a \leq x<b \\ \frac{c-x}{c-b} & \text { for } b \leq x \leq c\end{cases}
$$

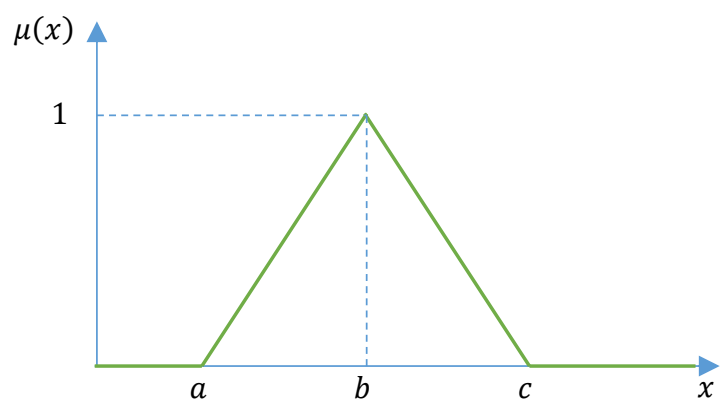

Fig. 1: Triangular membership function

$$
x^{\prime}=\frac{\sum_{i=1}^{n} x_{i} \cdot \mu\left(x_{i}\right)}{\sum_{i=1}^{n} \mu\left(x_{i}\right)}
$$




\section{Experimental Details}

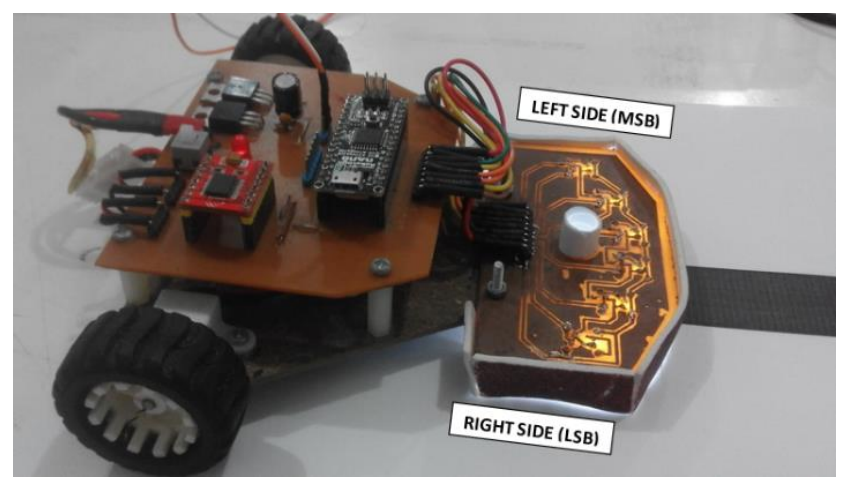

Fig. 2: Line follower robot prototype

LFR diagram is shown in Fig. 3 consist of three part of main hardware; it is line sensor, Arduino Nano, and motor driver. The line sensor is built from the six-sensor array with distance between sensors of $2 \mathrm{~cm}$. Each sensor connected to an ADC canal which goes through to the fuzzification section. The crisp value of line sensors reading has a universe of discourse $(\mathrm{UoD})$ that specified from 0 to 10 .

While the LFR move for the first time at the first sampling, the line sensor readings were stored to new position variable. In the next sampling, the value of new position variable was moved into old position variable, and so on for the following sampling. Both input variables have three linguistic variables which are left, right and straight which illustrated in Fig. 4 and Fig. 5. The changes of both variables become the foundation to build if-then rules which illustrated in Fig. 10 and Fig. 11. Output variables have three linguistic variables which is negative, zero and positive which illustrated in Fig. 6. Optimization is done by narrowing the universe of discourse in the straight and zero variables, which illustrated in Fig. 7, Fig. 8, and Fig. 9.

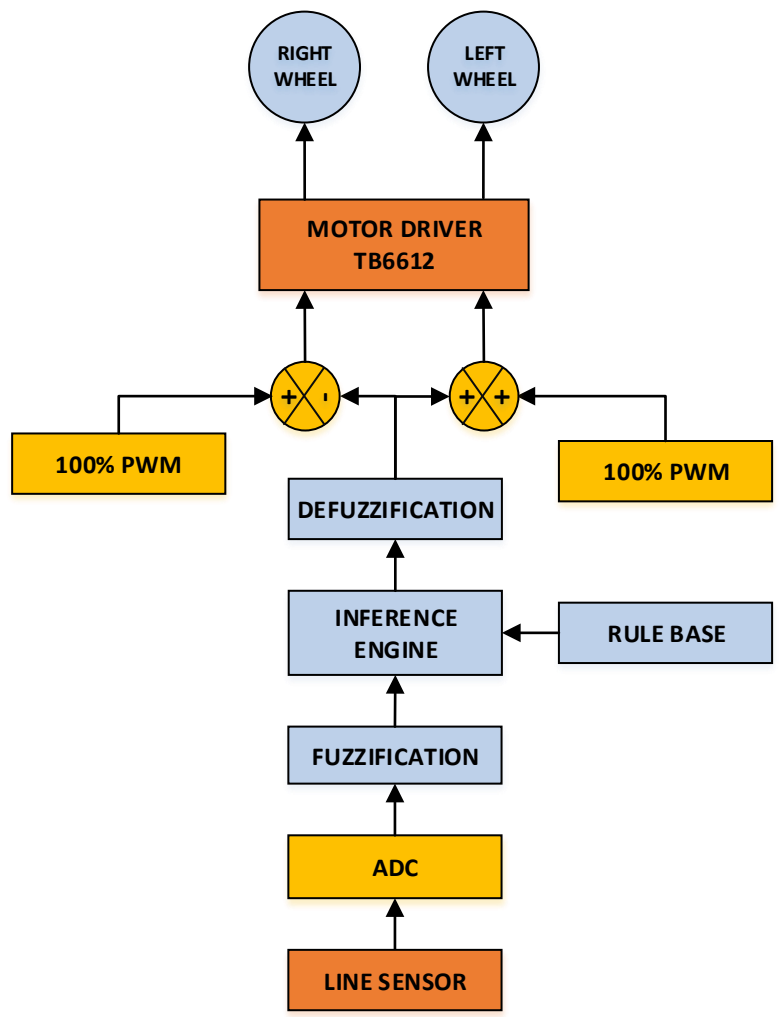

Fig. 3: Block Diagram of Line follower robot prototype

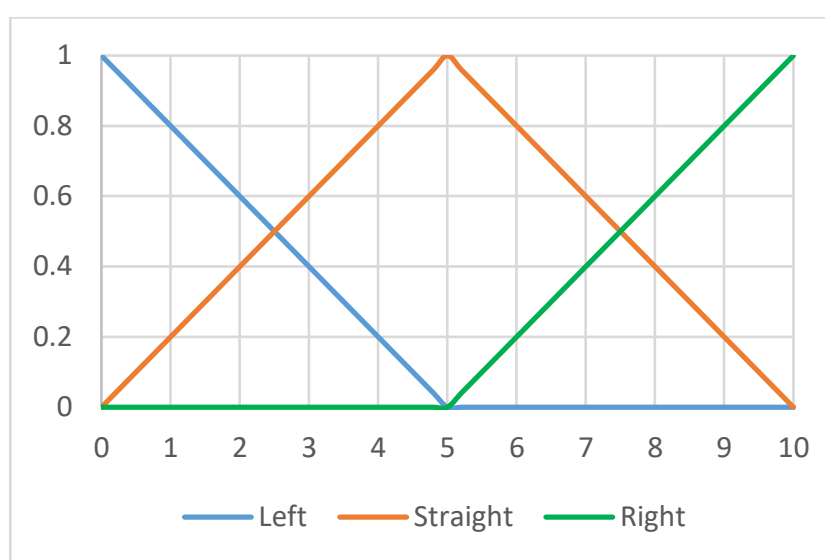

Fig. 4: Old-position variable before tuning

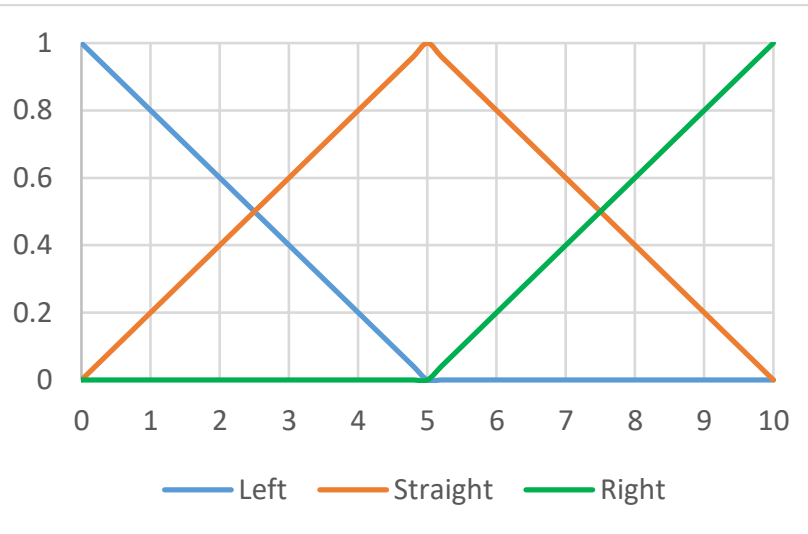

Fig. 5: New-position variable before tuning

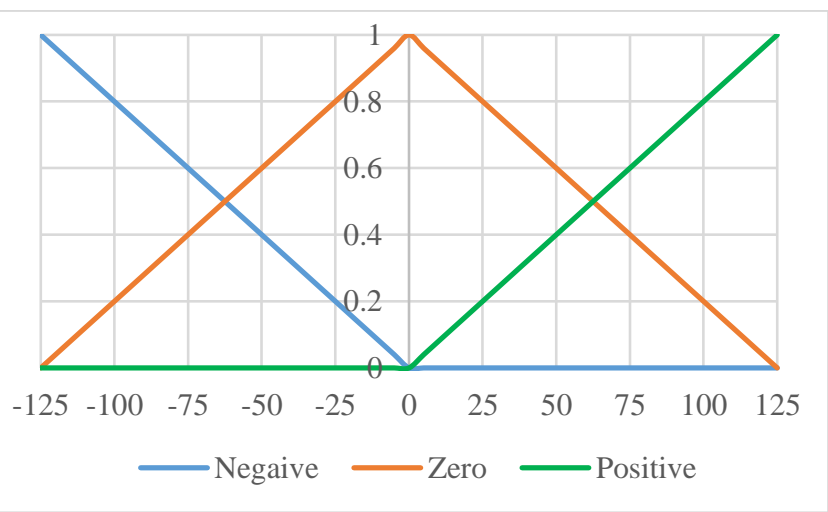

Fig. 6: Deviation variable before tuning

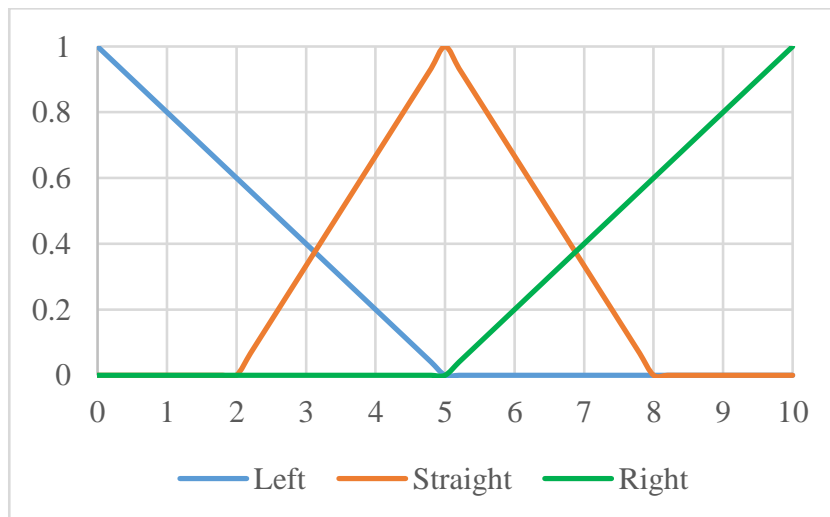

Fig. 7: Old-position variable after tuning 


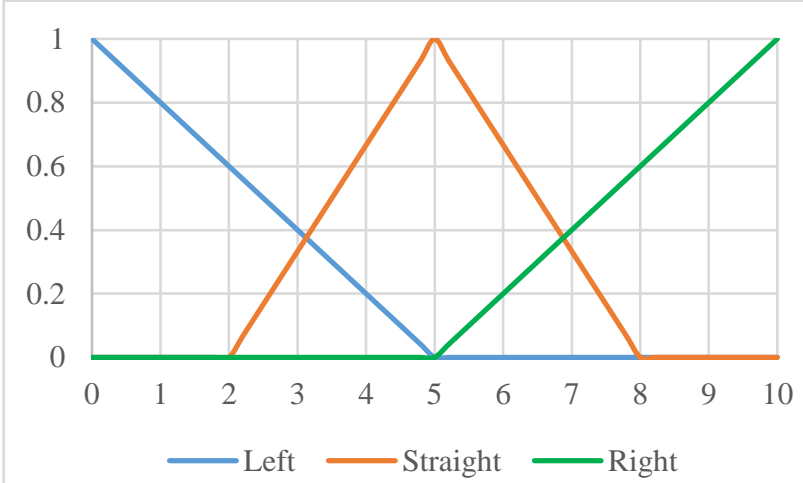

Fig. 8: New-position variable after tuning

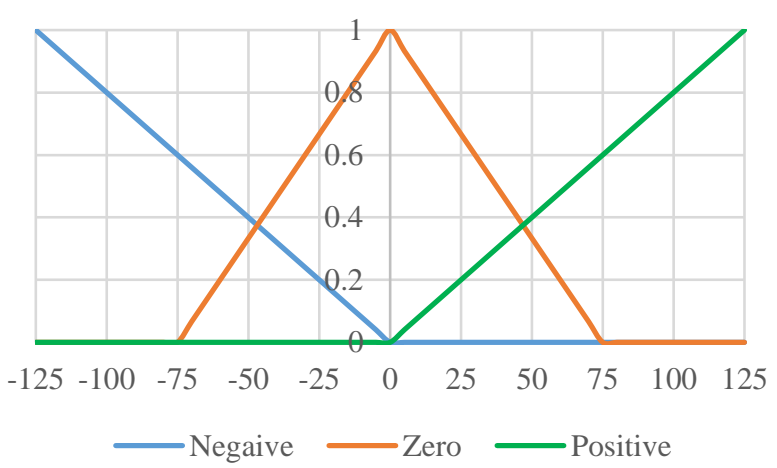

Fig. 9: Deviation variable after tuning

Of the three input-linguistic variables and the three variable-linguistic outputs, yields the following 9 bases of rules

$\mathrm{R} 1$ : if old-position is left and new-position is left, then deviation is positive

R2: if old-position is left and new-position is straight, then deviation is zero

R3: if old-position is left and new-position is right, then deviation is negative

R4: if old-position is straight and new-position is left, then deviation is positive

R5: if old-position is straight and new-position is straight, then deviation is zero

R6: if old-position is straight and new-position is right, then deviation is negative

R7: if old-position is right and new-position is left, then deviation is positive

R8: if old-position is right and new-position is straight, then deviation is zero

R9: if old-position is right and new-position is right, then deviation is negative

The output variable deviation has a UoD value of -125 to +125 and has three linguistic variables of negative, positive and zero. The deviation value is used to reduce the PWM value of right motor and to increase the PWM value of the left motor. In this experiment, a $100 \%$ PWM value is equal to 255 .
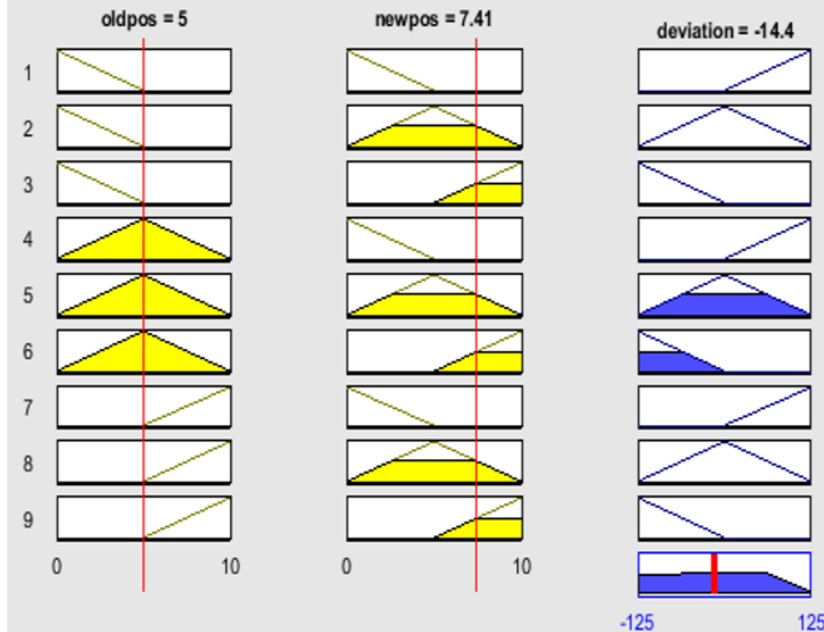

Fig. 10: Ruler based view of Fuzzy Logic Controller Without tuning
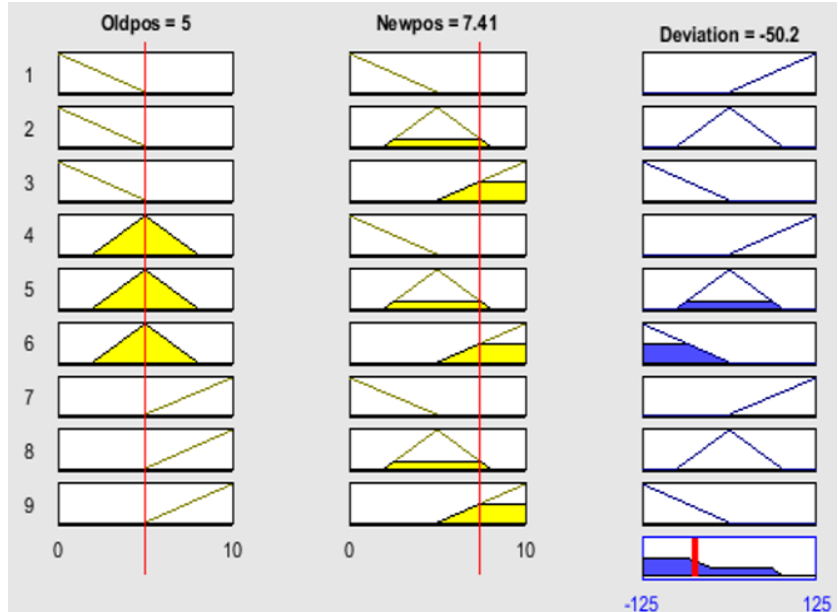

Fig. 11: Ruler based view of Fuzzy Logic Controller With tuning

Defuzzification using centroid method on aggregation result of all rules is shown in Fig. 10 and Fig. 11, both before and after tuning. MF tuning is conducted through adjustment of its linguistic values. The result of defuzzification than stored to deviation variable.

For the testing purpose, the path is a black straight line with $120 \mathrm{~cm}$ long and $2.5 \mathrm{~cm}$ thick on a white surface. Line sensor reading was captured every $100 \mathrm{~ms}$ and sent using serial communication. Gathered data from the acquisition, 30 data with $100 \mathrm{~ms}$ sampling time, then processed using Excel.

\section{Results and Discussion}

The performance test is shown in Fig. 12, Fig. 13, and Fig. 14 which is without MF tuning and Fig. 15, Fig. 16, and Fig. 17 which is with tuning. Each test was conducted five times. The default reference value is 5 of UoD which is from 0 to 10 . The starting position of LFR is parallel to the line path, with the LSB of line sensor directly above the line. So that the starting point in Fig. 12 and Fig. 15 is $(0,0)$ both with and without MF tuning. The LFR response time without tuning are $1600 \mathrm{~ms}, 1800 \mathrm{~ms}, 1600 \mathrm{~ms}, 1700 \mathrm{~ms}$ and $1500 \mathrm{~ms}$ consecutively, while with tuning are $600 \mathrm{~ms}, 700 \mathrm{~ms}, 600 \mathrm{~ms}, 550 \mathrm{~ms}$, $700 \mathrm{~ms}$. The average settling time is $1.64 \mathrm{~s}$ for LFR without MF tuning compare to $0.63 \mathrm{~s}$ with tuning. 


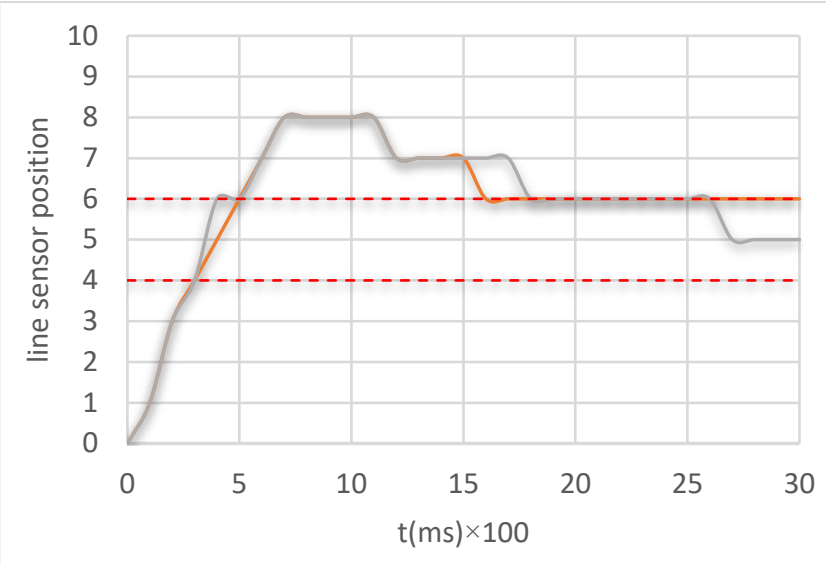

1st test 2 nd test $\quad \ldots--$ tolerance band

Fig. 12: LFR performance without MF tuning

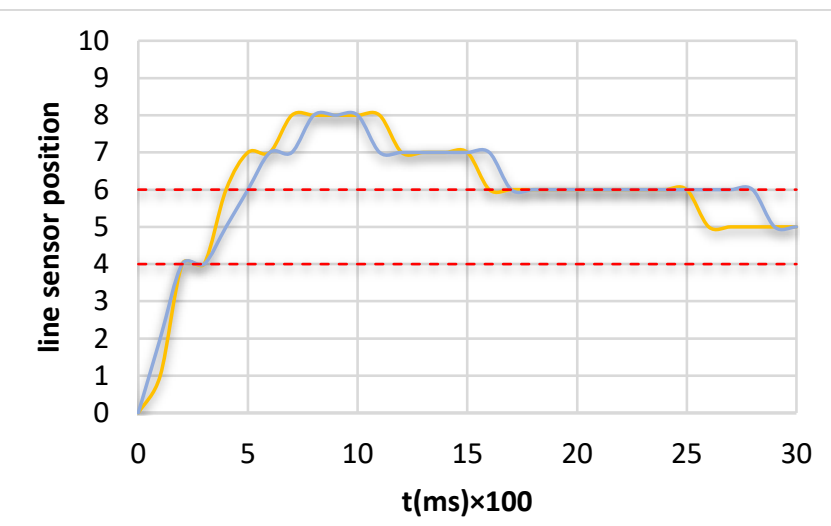

3rd test 4 th test $\ldots-\ldots$ tolerance band

Fig. 13: LFR performance without MF tuning

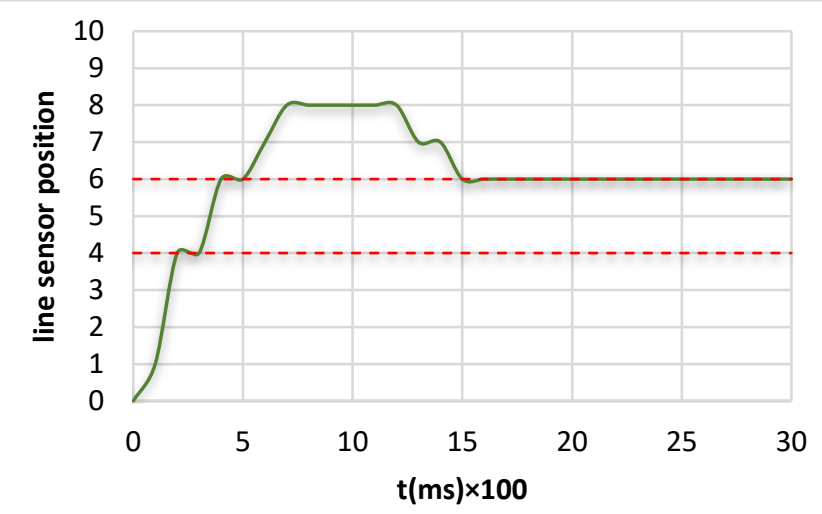

- 5th test $\quad-----$ tolerance band

Fig. 14: LFR performance without MF tuning

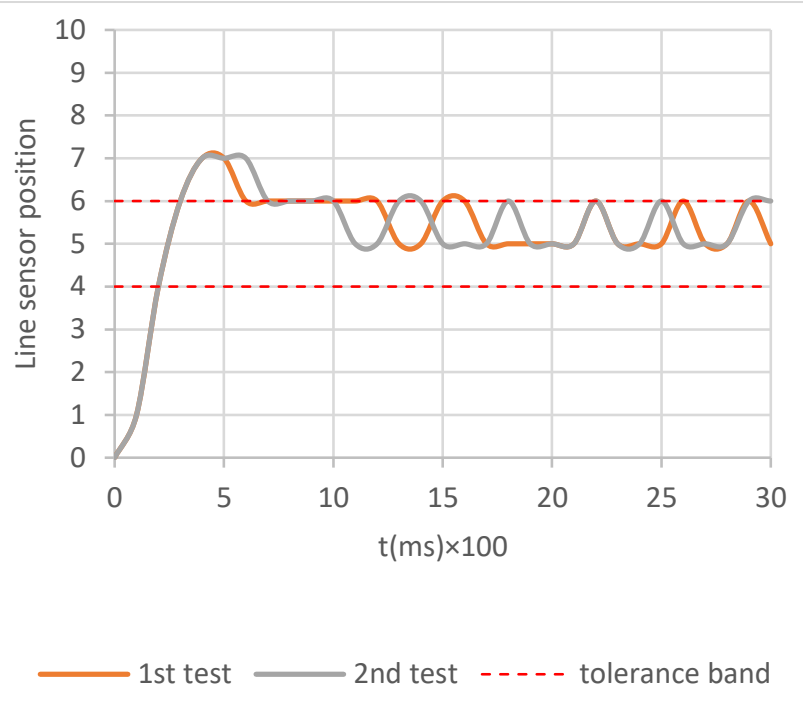

Fig. 15: LFR performance with MF tuning

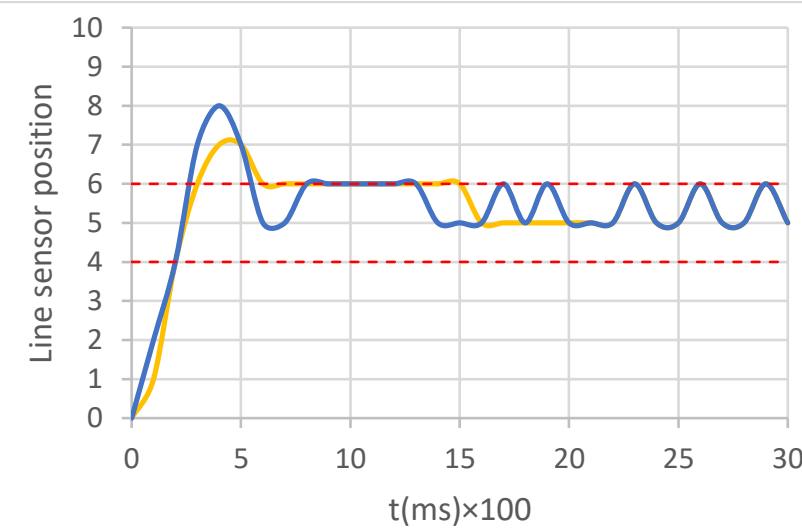

3rd test 4 th test $\ldots .-$ tolerance band

Fig. 16: LFR performance with MF tuning

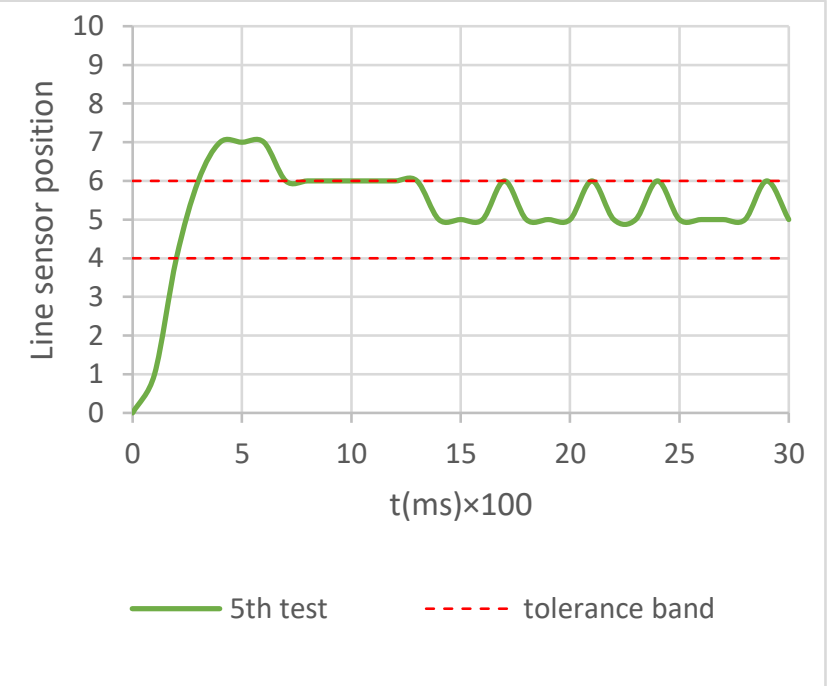

Fig. 17: LFR performance with MF tuning 


\section{Conclusion}

It is known from the experiment that triangular MF tuning on all variables to give better result while reaching the reference point to compare to that without tuning. The future work that will conduct in order to investigate the implementation of FLC on LFR are comparing the performance of different membership functions.

\section{Acknowledgement}

We appreciate the State Polytechnic of Samarinda (under contract SP DIPA 024.04.02.401010/2017) for providing financial support.

\section{References}

[1] T. Jain, R. Sharma, and S. Chauhan, "Applications of Line Follower Robot in Medical Field," Int. J. Res., vol. 1, no. 11, pp. 409-412, 2014

[2] M. Pakdaman, M. M. Sanaatiyan, and M. R. Ghahroudi, A line follower robot from design to implementation: Technical issues and problems, no. April 2010. 2010.

[3] D. Punetha, N. Kumar, and V. Mehta, "Development and Applications of Line Following Robot Based Health Care Management System," Int. J. Adv. Res. Comput. Eng. Technol., vol. 2, no. 8, pp. 2446-2450, 2013.

[4] R. K. Sure and S. Patil, "Android Based Autonomous Coloured Line Follower Robot," pp. 368-373, 2014.

[5] C. K. Justice, A.Vandana, "Controlling of Nonlinear System By Using Fuzzy Logic Controller," pp. 648-656, 2015.

[6] A. H. Ismail, A. M. A. Zaman, and K. Terashima, "Fuzzy Logic
Approach for Line Following Mobile Robot Using an Array of Digital Sensors FUZZY LOGIC APPROACH FOR LINE FOLLOWING MOBILE ROBOT USING AN ARRAY OF DIGITAL SENSORS," vol. 11, no. July, pp. 11827-11831, 2016.

[7] K. D. Sharma, M. Ayyub, S. Saroha, and A. Faras, "Advanced Controllers Using Fuzzy Logic Controller ( FLC ) for Performance Improvement," vol. 5, no. 6, pp. 1452-1458, 2014.

[8] O. Castillo, H. Neyoy, J. Soria, P. Melin, and F. Valdez, A new approach for dynamic fuzzy logic parameter tuning in Ant Colony Optimization and its application in fuzzy control of a mobile robot, vol. 28, no. March. 2015.

[9] Y. Li et al., "An improved line following optimization algorithm for mobile robot," Comput. Converg. Technol. (ICCCT), 20127 th Int. Conf., no. June 2013, pp. 84-87, 2012.

[10] J. A. Ali, M. A. Hannan, A. Mohamed, and M. G. M. Abdolrasol, "Fuzzy logic speed controller optimization approach for induction motor drive using backtracking search algorithm," Measurement vol. 78, no. September 2015, pp. 49-62, 2016.

[11] V. Castano, D. Rangel-Miranda, D. Alaniz-Lumbreras, and E. Olvera-Gonzálezb, "Fuel flow control through a fuzzy servomechanism: a comparative analysis," Int. J. Eng. Technol., vol. 3, no. 4, p. 506, 2014

[12] A. COMPAORE, K. SOME, and B. SOME, "New approach to the resolution of triangular fuzzy linear programs: MOMA-plus method.," Int. J. Appl. Math. Res., vol. 6, no. 4, p. 115, 2017.

[13] A. Widyotriatmo, P. I. Siregar, and Y. Y. Nazaruddin, "Line following control of an autonomous truck-trailer," 2017 Int. Conf. Robot. Biomimetics, Intell. Comput. Syst., no. December 2017, pp. 24-28, 2017.

[14] M. B. Soparkar, "Defuzzification in a Fuzzy Logic Controller: Automatic Washing Machine," Int. J. Comput. Appl., no. Icct, pp. 975-8887, 2015

[15] A. D. Kulkarni, Computer Vision and Fyzzy-Neural Systems. Prentice Hall PTR, 2001 